\title{
The Rotor Speed Choice of Signal Acquisition in a Ball Bearing-rotor System with a Raceway Local Defect Based on Dynamic Analysis
}

\author{
Rui Yang, Lei Hou* and Yushu Chen \\ School of Astronautics, Harbin Institute of Technology, Harbin 150001, P. R. China \\ ${ }^{*}$ Corresponding author
}

\begin{abstract}
We intend to exploit the vibration status such as the resonance existed in a faulty bearing-rotor system on signal acquisition for diagnosis in this paper. We establish a symmetrical bearing-rotor-pedestal system to do the dynamic response analysis. The theoretical analysis indicates the resonances excited by the excitations can enhance the response in low-frequency range as well as the response in high-frequency range because the pulse energy produced by bearing defect increases under this situation. Finally, these conclusions are verified qualitatively by the experiment.
\end{abstract}

Keywords-bearing local defect; ball bearing-rotor system; resonances; envelope analysis

\section{INTRODUCTION}

Rolling bearings are key elements in a rotating machinery such as the aero-engine, and many scholars have paid great attention to a faulty bearing to get rid of the breakdowns. the majority of the current literature involving a faulty bearing is mainly focused on the dynamic modelling and diagnosis. The following brief literature introduction concentrates on these two aspects.

McFadden and Smith [1], one of the earliest teams worked on the bearing defect model, combined the impact force function, the load condition, speed and transfer path to describe the local defect for inner race defect, and they presented the frequency spectrum of a faulty bearing as well. Tandon and Choudhury $[2,3]$ though the pulse should have a duration, and modelled the pulse as an accumulation of trigonometric series, the mode superposition method was used to gain the response of the system of under the defect. Sassi et al. [4] assumed the hitting process is conservative, they put up a new impacting force model for bearing defect by exploiting the energy conservation theorem and the law between the impact force and shock velocity. Khanam et al. [5] proposed excitation force model by using the mechanic principles to identify local bearing fault, the whole process for the ball hitting the defect was clearly described. Another major work on the defect modeling tries to depict the geometry boundary variation, this model essentially describes the clearance change in the defective zone. Feng et al. [6] modeled the local defect with an angle span and a depth via a step function to be the switch. Sopanen and Mikola [7] modeled the local defect via a switch function. Sawalhi and Randall [8] introduced a rough surface topography function to depict an extended fault. Tadina and Boltezar [9] established the governing equation of defective bearing system via a hybrid method of multi-dynamics and finite element method. Liu et al. [10] proposed a piecewise function model to describe the local defect. Niu et al. [11] established a comprehensive dynamic model to explore the high-speed vibration response. In 2015, Singh et al. [12] and Thalji et al. [13] reviewed the current literatures on the faulty bearing modelling, respectively. Compared to the dynamic and defect model study of a defective bearings system, a huge amount papers focus on the feature extraction and diagnostic on a faulty bearing. The methods related can be broadly divided into time-domain, frequencydomain and time-frequency domain methods. The domainmethods usually depend on some statistical parameters such as the singular spectrum analysis [14]. The fast Fourier transform is a standard frequency-domain method, and it usually combines some other domain method, such as envelope analysis [15]. The time-frequency methods are very popular method in field of feature extraction and diagnostics of a faulty bearing such as the Wavelet transform [16]. Besides, many techniques are exploited to remove the interference factors to improve the signal quality such as the background noise [17].

Despite the fruitful achievements, few papers focus on the relationship between the response and different vibration status because the one frequency is best seen in the majority of current literatures. It is blind to choose the rotor speed for signal acquisition. Therefore, this paper tries to explore the signal enhancement based on the internal dynamic mechanism of a bearing-rotor system and find out the regularities.

\section{MODELLING PROCESS}

The rotor is assumed to be symmetrical and rigid, with two same ball bearings supported at two ends. Referred to Figure $\mathrm{I}(\mathrm{a})$, the overall contact deformation for the $j$ th rolling element $\delta_{j}$ is a function of the rotor displacement $\left(x_{\mathrm{r}}, y_{\mathrm{r}}\right)$ relative to the pedestal displacement $\left(x_{\mathrm{p}}, y_{\mathrm{p}}\right)$ in the $\mathrm{x}$ - and $\mathrm{y}$-directions, the rolling element position $\theta_{j}$ and the radial clearance $2 \delta_{0}[6]$, 


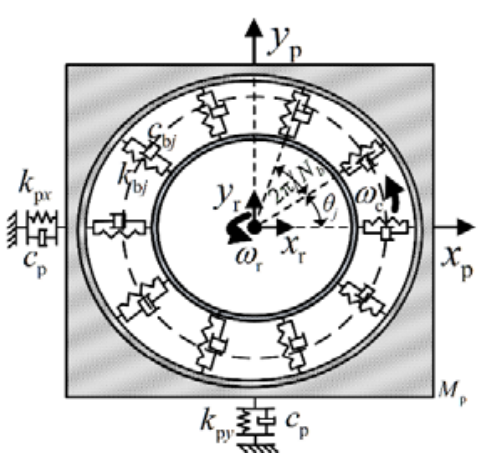

(a)

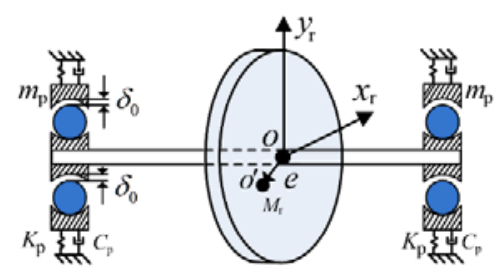

(b)

FIGURE I. SCHEMATIC OF SIMPLIFIED RIGID ROTOR-BEARING SYSTEM (A) SIMPLIFIED BALL-BEARING-PEDESTAL MODEL (B) SYMMETRICAL ROTOR-BEARING

$$
\delta_{j}=\left(x_{\mathrm{r}}-x_{\mathrm{p}}\right) \cos \theta_{j}+\left(y_{\mathrm{r}}-y_{\mathrm{p}}\right) \sin \theta_{j}-\delta_{0},
$$

the angular positions of the rolling elements $\theta_{j}$ are functions of time increment $t$, the cage speed $\omega_{c}$

$$
\theta_{j}=2 \pi(j-1) / N_{b}+\omega_{c} t
$$

where $\omega_{c}$ is determined by the bearing geometry structure and the rotor speed,

$$
\omega_{c}=B_{0} \omega_{\mathrm{r}}
$$

where $B_{\mathrm{o}}=D_{\mathrm{i}} /\left(D_{\mathrm{i}}+D_{\mathrm{o}}\right), D_{\mathrm{i}}$ is diameter of the inner race, $D_{\mathrm{o}}$ is the diameter of the outer race.

The load deflection factor $k_{\mathrm{b}}$ depends on the contact geometry and the elastic contacts of the material [18],

$$
Q_{j}=k_{\mathrm{b}} \delta_{j}^{1.5}
$$

$$
\begin{gathered}
f_{x}=\sum_{j=1}^{N_{b}} G\left(\delta_{j}\right) Q_{j} \cos \theta_{j}, \\
f_{y}=\sum_{j=1}^{N_{b}} G\left(\delta_{j}\right) Q_{j} \sin \theta_{j},
\end{gathered}
$$

where $G(\cdot)$ is the Heaviside function, $G\left(\delta_{j}\right)= \begin{cases}0, & \delta_{j}<0 \\ 1, & \delta_{j} \geq 0 .\end{cases}$

A classical rectangular defect model is adopted, additional deformation is introduced into Eq. (1) as a ball runs over the defect zone, which is illustrated in Figure II. The contact deformation of jth element in Eq. (1) changes,

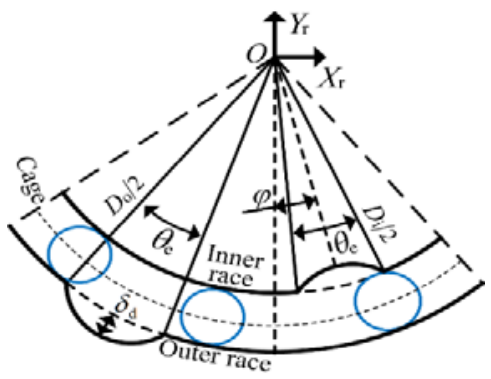

FIGURE II. SCHEMATIC DIAGRAM OF A DEFECTIVE BEARING

$$
\delta_{j}=\left\{\begin{array}{cl}
\delta_{j}-\delta_{\mathrm{d}}, & \left|\theta_{\mathrm{bd} j}\right|<\theta_{e} / 2, \\
\delta_{j} & \left|\theta_{\mathrm{bdj} j}\right| \geq \theta_{e} / 2,
\end{array}\right.
$$

where $\theta_{\mathrm{e}}$ is the span of the defect (see Figure II), $\delta_{\mathrm{d}}$ is the depth of the defect, $\theta_{\mathrm{bd} j}$ is the angular difference between $j$ th rolling element and the local defect, denoted as

$$
\theta_{\mathrm{bdj}}=\left\{\begin{array}{cc}
\bmod \left(\omega_{\mathrm{r}} t, 2 \pi\right)-\bmod \left(\omega_{c} t, 2 \pi\right), & \text { Inner racedefect }, \\
\bmod \left(\theta_{j}, 2 \pi\right)-\varphi, & \text { Outerracedefect },
\end{array}\right.
$$

where $\bmod (\cdot)$ is the function calculating the remainder after division, $\varphi$ is the defect angle (Figure II(b)).

A dimensionless process is introduced, make $\omega_{\mathrm{r}} t=\tau, x_{\mathrm{r}} / \delta_{0}=X_{\mathrm{r}}$, $y_{\mathrm{r}} / \delta_{0}=Y_{\mathrm{r}}, x_{\mathrm{p}} / \delta_{0}=X_{\mathrm{p}}, y_{\mathrm{p}} / \delta_{0}=Y_{\mathrm{p}}, e / \delta_{0}=E$, the governing equation can be established,

Summing Eq. (5) in the $x$ - and $y$-directions for $N_{\mathrm{b}}$ balls, the total force can be calculated as follows,

$$
\begin{gathered}
m_{\mathrm{r}} \ddot{X}_{\mathrm{r}} \omega_{\mathrm{r}}^{2}+c_{\mathrm{b}}\left(\dot{X}_{\mathrm{r}}-\dot{X}_{\mathrm{p}}\right) \omega_{\mathrm{r}}+\delta_{0}^{0.5} f_{x}\left(X_{\mathrm{r}}-X_{\mathrm{p}}\right)=m_{\mathrm{r}} E \omega_{\mathrm{r}}^{2} \cos (\tau), \\
m_{\mathrm{r}} \ddot{Y}_{\mathrm{r}} \omega_{\mathrm{r}}^{2}+c_{\mathrm{b}}\left(\dot{Y}_{\mathrm{r}}-\dot{Y}_{\mathrm{p}}\right) \omega_{\mathrm{r}}+\delta_{0}^{0.5} f_{y}\left(Y_{\mathrm{r}}-Y_{\mathrm{p}}\right)=m_{\mathrm{r}} E \omega_{\mathrm{r}}^{2} \sin (\tau)-m_{\mathrm{r}} g / \delta_{0},
\end{gathered}
$$




$$
\begin{gathered}
m_{\mathrm{p}} \ddot{X}_{\mathrm{p}} \omega_{\mathrm{r}}^{2}+c_{\mathrm{p}} \dot{X}_{\mathrm{p}} \omega_{\mathrm{r}}+k_{\mathrm{p}} X_{\mathrm{p}}-\delta_{0}^{0.5} f_{x}\left(X_{\mathrm{r}}-X_{\mathrm{p}}\right)-c_{\mathrm{b}}\left(\dot{X}_{\mathrm{r}}-\dot{X}_{\mathrm{p}}\right) \omega_{\mathrm{r}}=0 \\
m_{\mathrm{p}} \ddot{Y}_{\mathrm{p}} \omega_{\mathrm{r}}^{2}+c_{\mathrm{p}} \dot{Y}_{\mathrm{p}} \omega_{\mathrm{r}}+k_{\mathrm{p}} Y_{\mathrm{p}}-\delta_{0}^{0.5} f_{y}\left(Y_{\mathrm{r}}-Y_{\mathrm{p}}\right)-c_{\mathrm{b}}\left(\dot{Y}_{\mathrm{r}}-\dot{Y}_{\mathrm{p}}\right) \omega_{\mathrm{r}}=0
\end{gathered}
$$

where $m_{\mathrm{r}}$ is half of the rotor mass, $m_{\mathrm{p}}$ is the pedestal mass.

\section{NUMERICAL SIMULATION}

In this section, we will discuss the speed effect on system response and the corresponding signal quality. The parameters used in this paper are listed in Table I. Besides, the outer defect is assumed right in the middle of the load zone.

TABLE I. THE PARAMETERS OF THE RIGID ROTOR BEARING SYSTEM [6]

\begin{tabular}{cccc}
\hline Parameters of the system & Values & Parameters of the system & Values \\
\hline Rotor mass $M_{\mathrm{r}}(\mathrm{kg})$ & 140 & Damping of pedestal $c_{\mathrm{p}}(\mathrm{Ns} / \mathrm{m})$ & 1000 \\
Half of rotor mass $m_{\mathrm{r}}(\mathrm{kg})$ & 70 & Speed ratio of rotor and cage $B_{\mathrm{o}}$ & 0.39 \\
Pedestal mass $m_{\mathrm{p}}(\mathrm{kg})$ & 10 & The number of rolling element $N_{\mathrm{b}}$ & 8 \\
Stiffness of ball beaing $k_{\mathrm{b}}(\mathrm{N} / \mathrm{m})$ & $1.4 \times 10^{10}$ & Eccentricity $(\mathrm{m}) e$ & $2 \times 10^{-5}$ \\
Stiffness of pedestal $k_{\mathrm{p} x}(\mathrm{~N} / \mathrm{m})$ & $2.1 \times 10^{7}$ & Radial clearance $(\mathrm{m}) 2 \delta_{0}$ & $1 \times 10^{-5}$ \\
Stiffness of pedestal $k_{\mathrm{p} y}$ & $3.1 \times 10^{7}$ & Span of defect $\theta_{\mathrm{e}}(\mathrm{rad})$ & 0.1 \\
Damping of ball bearing $c_{\mathrm{b}}(\mathrm{Ns} / \mathrm{m})$ & 200 & Depth of the defect $\delta_{\mathrm{d}}(\mathrm{m})$ & $1 \times 10^{-3}$ \\
\hline
\end{tabular}

A mature technique - envelope analysis is used to analyze the dynamic response because it has been used for decades [15]. Moreover, the spectrum kurtosis (SK) based envelope is exploited [19].

The pedestal responses at multiple speeds are analyzed by the envelope analysis to illustrate the effect on the analysis results. Figure III presents analysis results of pedestal at two different speeds for inner race defect Figure III(a) and outer race defect Figure III(b). Figure III(a) shows analysis results at 900 rpm, while Figure III(b) displays the analysis results at 800 . The kurtogram of $\mathrm{SK}$, original signal and squared envelope spectrums of filtered signal of the pedestal response are contained in each figure, respectively. It is obvious that the time-domain response in Figure III(a) is the typical response in the time-domain [15] where the pulse produced by local defect is modulated by the rotor rotation. The inner race defect frequency BPFI and its harmonics are clearly displayed in the squared envelope spectrums in Figure III(a). Besides, the rotor eccentric frequency also appears in the frequency spectrum. By contrast, the situation is a litter different when it comes to the outer race defect. The time responses in Figure III(b) are typical response for outer race defect [15], but the pulses in Figure III(b) exhibits uniformity. Similar to the inner race defect, the outer race defect frequency $\mathrm{BPFO}$ and its harmonics are clearly presented in the frequency spectrum.
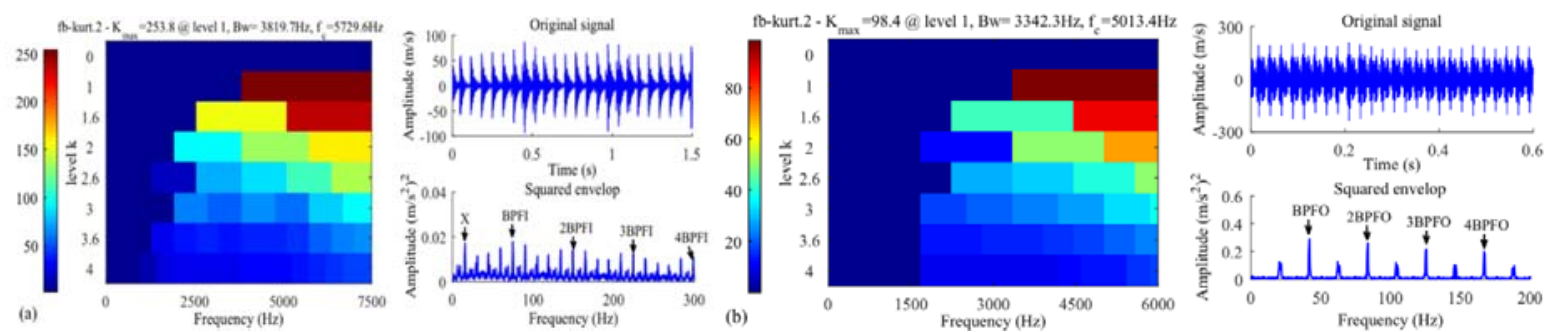

FIGURE III. THE KURTOGRAM OF SK, ORIGINAL SIGNAL AND CORRESPONDING SQUARED ENVELOPE OF PEDESTAL SIGNAL. (A) INNER DEFECT AT 900 RPM; (B) INNER DEFECT AT 1800 RPM; (C) OUTER DEFECT AT 800 RPM; (D) OUTER DEFECT AT 1600 RPM

In addition, the variation trend becomes more obvious if we extract the amplitudes of defect frequencies in the envelope spectrums. The envelope spectrum curves at different speeds are displayed in Figure IV. The effect on the envelope analysis results is clearly presented in the figure where many peaks exist. In Figure IV(a), the obvious peaks are around $1400 \mathrm{rpm}, 1700$ $\mathrm{rpm}$ and $2500 \mathrm{rpm}$. Similarly, the resonance peaks around 800 $\mathrm{rpm}$ and $1600 \mathrm{rpm}$. By contrast the results in Figure IV(a) to Figure IV(b), the envelope analysis results of outer race defect is more sensitive than that of the inner race defect. Moreover, they still reflect the vibration status such as the resonance characteristics on the signal analysis results. The physical explanation for these phenomena is that the resonance aggravates the energy of the contact-collision process during the element hitting the local defect, and the increased hitting energy increases the amplitude of the pulses and the corresponding high-frequency resonance amplitude such as the pedestal resonance. 

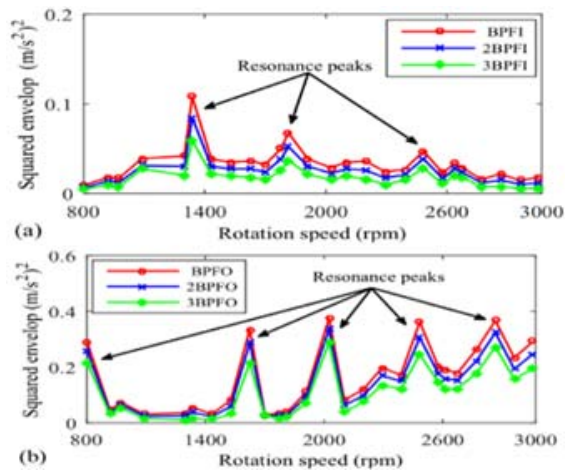

FIGURE IV. THE ENVELOPE SPECTRUM CURVES AT DIFFERENT SPEEDS. (A) INNER DEFECT; (B) OUTER DEFECT

\section{EXPERIMENTAL RESULTS}

The experiment system is illustrated in Figure VII. The bearings used in this paper are 6312 deep groove ball bearing, and its parameters are listed in Table II. The system consists of 3 parts: (a) the test rig of a bearing rotor system and power system; (c) the power controlling system and signal acquisition system. In this part, we collect and analyze the vibration data from the pedestal at multiple rotation speeds. The sample rate for current eddy sensor is set as $16384 \mathrm{~Hz}$, and it is $20 \mathrm{kHz}$ for the acceleration sensor. The change of rotor rotation speed is in sequence, and the step is about $200 \mathrm{rpm}$. It lasts $10 \mathrm{~s}$ for every step to gain steady vibration response. The limit of the rotor speed is set around $3000 \mathrm{rpm}$ considering the safety.

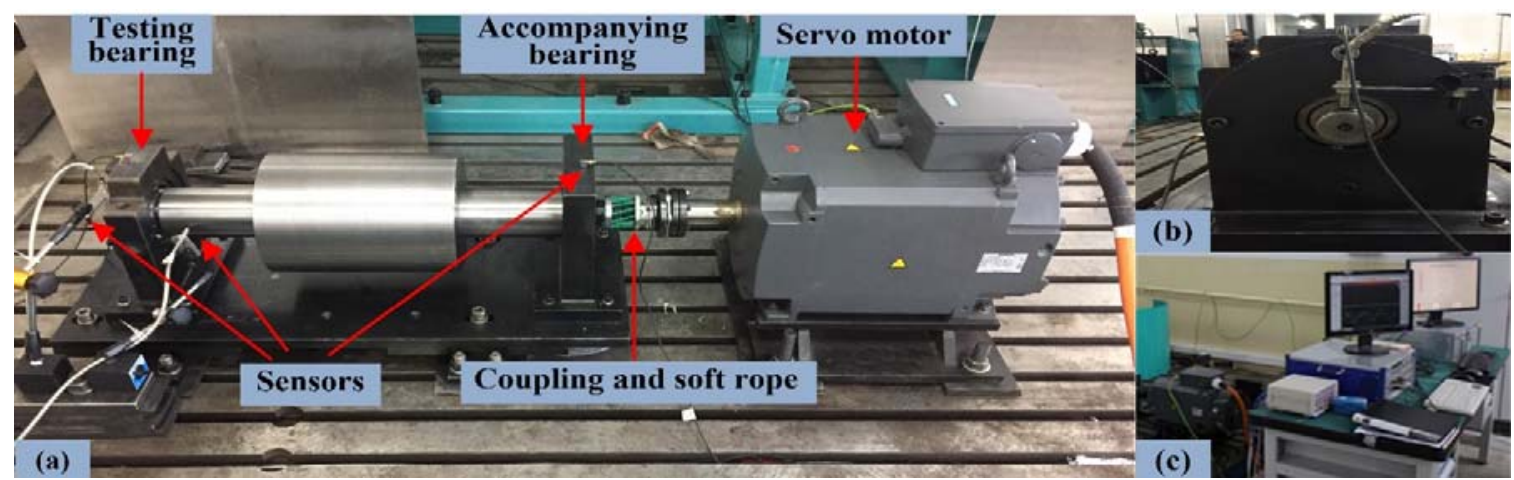

FIGURE V. EXPERIMENT SYSTEM. (A) BEARING ROTOR SYSTEM AND THE POWER SYSTEM; (B) SENSORS INSTALLATION FOR THE TESTED BEARING; (C) POWER CONTROLLING SYSTEM AND SIGNAL ACQUISITION SYSTEM

The envelope analysis of two different speeds (1500 rpm and 3000 rom) for inner race defect and outer race defect are accomplished to detect the analysis results in high-frequency range. Figure $X(a)(b)$ shows results of the inner race defect and the Figure $X(c)(d)$ exhibits the outcome of the outer race defect. The results are obtained by exploiting envelope analysis to the de-noised experimental vibration signal. For the inner race defect in Figure X (a)(b), we can gain the basic BPFI and the harmonics, however, we can only the obtain the basic BPFO in Figure $X(c)(d)$. One interesting phenomenon is the occurrence of BPFO in the Figure X (a), while it does not emerge in the Figure $\mathrm{X}(\mathrm{b})$. It may because the test bearing is slightly damaged during installation. Besides, the envelope spectrums in Figure $\mathrm{X}(\mathrm{b})(\mathrm{d})$ in the $\mathrm{VC}$ resonance (we obtained the resonance characteristics by a hammer test) are clearer than those in Figure $\mathrm{X}(\mathrm{a})(\mathrm{c})$ in the non-VC resonance by contrasting the amplitude and the neatness. These results show consistency with the former analysis results, and also proves the effect of the vibration status on the signal analysis results.

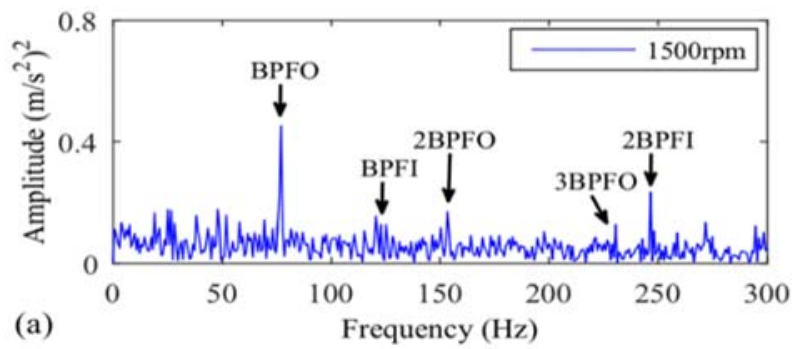

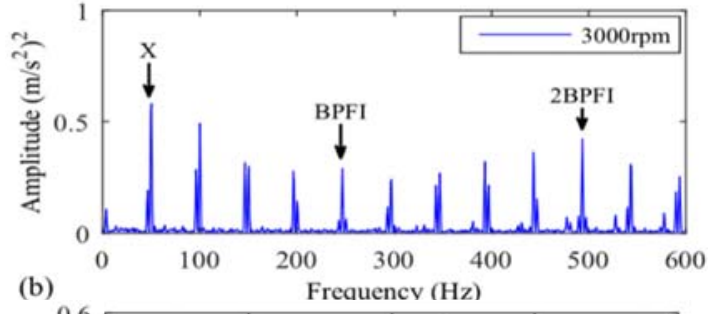
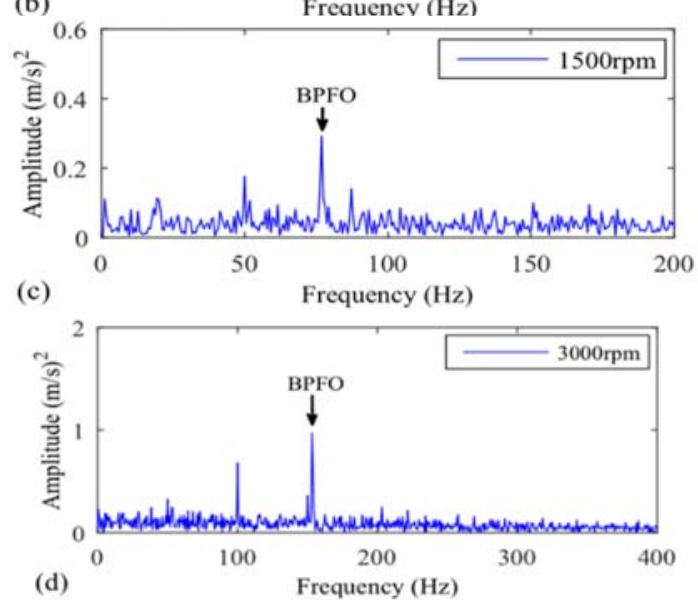

FIGURE VI. ENVELOPE SPECTRUMS OF INNER DEFECT AND OUTER DEFECT AT 1500 RPM AND 3000 RPM. (A)(B) INNER DEFECT; (C)(D) OUTER DEFECT 


\section{CONCLUSION}

We establish a bearing-rotor-pedestal system with race defect to demonstrate that the vibration status has effects on the signal analysis results in this paper. Our theoretical and experiment results demonstrate the speed for acquisition influences the final analysis outcome. The resonance characteristics of a bearing rotor system can be estimated by the mode analysis in reality. Therefore, the blindness for the rotor speed choice in the diagnostic of the defective bearing can be avoided. A better analysis result for defective bearing rotor system may be received if combined the current diagnostic techniques.

\section{ACKNOWLEDGEMENTS}

The authors would like to acknowledge the financial supports from the National Key Basic Research Program (973 Program) of China (Grant No. 2015CB057400), the National Natural Science Foundation of China (Grant No. 11602070).

\section{REFERENCES}

[1] P.D. McFadden, J.D. Smith, Model for the vibration produced by a single point defect in a rolling element bearing, J. Sound Vib. 96 (1984) 69-82.

[2] N. Tandon; A. Choudhury, An analytical model for the prediction of the vibration of response pf rolling bearings due to a local deffect, J. Sound Vib. 205 (1997) 275-292.

[3] A. Choudhury, N. Tandon, A theoretical model to predict the vibration response of rolling bearings in a rotor bearing system to distributed defects under radial load, J. Tribol. Asme. 122 (1998) 609-615.

[4] S. Sassi, B. Badri, M. Thomas, A numerical model to predict damaged bearing vibrations, J. Vib. Control. 13 (2007) 1603-1628.

[5] S. Khanam, J.K. Dutt, N. Tandon, Impact Force Based Model for Bearing Local Fault Identification, ASME. J. Vib. Acoust. 137 (2015) 5100251013.

[6] N.S. Feng, E.J. Hahn, R.B. Randall, Using transient analysis software to simulate vibration signals due to rolling element bearing defects, in: Proc. 3rd Aust. Congr. Appl. Mech. Sydney, 2002, 2002: pp. 689-694.

[7] J. Sopanen, A. Mikkola, Dynamic Model of a Deep Groove Ball Bearing Including Localized and Distributed Defects, Part 1: Theory, Proc. Inst. Mech. Eng. Part K J. Multi-Body Dyn. 217(k) (2003) 201-211.

[8] N. Sawalhi, R.B. Randall, Simulating gear and bearing interactions in the presence of faults. Part II: Simulation of the vibrations produced by extended bearing faults, Mech. Syst. Signal Process. 22 (2008) 19521966.

[9] M. Tadina, M. Boltežar, Improved model of a ball bearing for the simulation of vibration signals due to faults during run-up, J. Sound Vib. 330 (2011) 4287-4301.

[10] J. Liu, Y. Shao, A new dynamic model for vibration analysis of a ball bearing due to a localized surface defect considering edge topographies, Nonlinear Dyn. 79 (2015) 1329-1351.

[11] L. Niu, H. Cao, Z. He, Y. Li, Dynamic Modeling and Vibration Response Simulation for High Speed Rolling Ball Bearings With Localized Surface Defects in Raceways, J. Manuf. Sci. Eng. 136 (2014) 041015.

[12] S. Singh, C.Q. Howard, C.H. Hansen, An extensive review of vibration modelling of rolling element bearings with localised and extended defects, J. Sound Vib. 357 (2015) 300-330.

[13] I. El-Thalji, E. Jantunen, A summary of fault modelling and predictive health monitoring of rolling element bearings, Mech. Syst. Signal Process. 60-61 (2015) 252-272.

[14] B. Muruganatham, M. a. Sanjith, B. Krishnakumar, S. a. V. Satya Murty, Roller element bearing fault diagnosis using singular spectrum analysis, Mech. Syst. Signal Process. 35 (2013) 150-166.

[15] R.B. Randall, J. Antoni, Rolling element bearing diagnostics-A tutorial, Mech. Syst. Signal Process. 25 (2011) 485-520.
[16] Z. Huo, Y. Zhang, P. Francq, L. Shu, J. Huang, Incipient Fault Diagnosis of Roller Bearing using Optimized Wavelet Transform based Multi-speed Vibration Signatures, IEEE Access. (2017) 2169-3536.

[17] J. Ma, J. Wu, Y. Fan, X. Wang, The Rolling Bearing Fault Feature Extraction Based on the LMD and Envelope Demodulation, Math. Probl. Eng. 2015 (2015) 1-13.

[18] T.A. Harris, M.N. Kotzalas, Essential concepts of bearing technology, CRC press, 2006.

[19] J. Antoni, The spectral kurtosis: A useful tool for characterising nonstationary signals, Mech. Syst. Signal Process. 20 (2006) 282-307. 